OMAE2006-92369

\title{
AIRBORNE ELECTROMAGNETIC SEA ICE THICKNESS SOUNDING IN SHALLOW, BRACKISH WATER ENVIRONMENTS OF THE CASPIAN AND BALTIC SEAS
}

\author{
Christian Haas \\ Alfred Wegener Institute for Polar Research, Bremerhaven, Germany
}

\begin{abstract}
Ice engineering projects often rely on the knowledge of ice thickness in shallow, brackish water like in the Baltic and Caspian Seas. By means of field data and model results, the paper shows that helicopter-borne electromagnetic induction measurements using frequencies of 3.68 and 112 $\mathrm{kHz}$ can yield accurate thickness estimates with salinities as low as 3 ppt. The higher frequency yields the strongest EM signals. In addition, in shallow water the higher frequency is less sensitive to the sea floor signal, and can thus be used in water depths as shallow as 4 to $6 \mathrm{~m}$, depending on flying altitude. Because the low frequency signal is very sensitive on shallow water depth, a combination of both signals will allow the retrieval of both ice thickness and water depth.
\end{abstract}

\section{INTRODUCTION}

Sea ice thickness is one of the most important parameters for ice engineering problems and climate studies. Apart from ice profiling sonar (IPS) measurements, electromagnetic induction (EM) thickness sounding has become an accurate and efficient method for thickness profiling (see description of method below) and can be operated on the ice, from ships (Haas, 1998; Haas et al., 1999), or from structures like lighthouses or oil rigs (Haas and Jochmann, 2003). However, EM sounding is most powerful when operated from helicopters (Kovacs and Holladay, 1990; Prinsenberg and Holladay 1993, Haas, 2004) or fixed-wing aircrafts (Multala et al., 1996).

The accuracy of EM thickness sounding increases with the salinity of the water below the ice (see below and references above). Unfortunately, in many key regions for ice engineering activities the salinity of the water is very low, like in the brackish waters of the Baltic and Caspian Seas. Haas (2004) has shown that accurate EM measurements are still possible down to sea water salinities of 3 ppt. In addition, there are large regions with very shallow water less than $10 \mathrm{~m}$ deep. Because the lowfrequency electromagnetic fields generated by EM instruments penetrate into the water (see below), they can also reach the sea floor and contribute to the measured secondary field strength. This could result in overestimates of ice thickness if the water depth is unknown or if the wrong signal frequencies are used (see below). On the other hand, induction in the sea floor enables to determine both ice thickness and water depth (Kovacs et al., 1987).

Here we show an example of EM thickness measurements in the shallow water of the Bay of Bothnia in the northernmost Baltic Sea using a small helicopter EM sensor, and some model results. They demonstrate the particularities of EM sounding in brackish water and that accurate ice thickness measurements are still possible with very low salinities of 3 ppt. In addition, it will be shown by means of model calculation and the data that EM ice thickness measurements in shallow water less than $10 \mathrm{~m}$ deep are possible with instruments using high frequencies.

\section{METHODS}

The measurements discussed here have been performed with a helicopter EM sensor on February 5, 2004, in the Bay of Bothnia south of the Finish island of Hailuoto (Figure 1). They were carried out in the framework of an international, 1.5 month long ice thickness monitoring program funded by the Ice Ridging Information for Shipping (IRIS) project of the European Union. The specific profile is discussed here because it crosses the $10 \mathrm{~m}$ isobath noted in the Bathymetric charts of the Baltic Sea Research Institute (IOW, Warnemünde, Germany). According to a Finish Hydrographic Office sea chart, water depths are only slowly increasing westwards to $20 \mathrm{~m}$, and range between 10 and $4.4 \mathrm{~m}$ to the east.

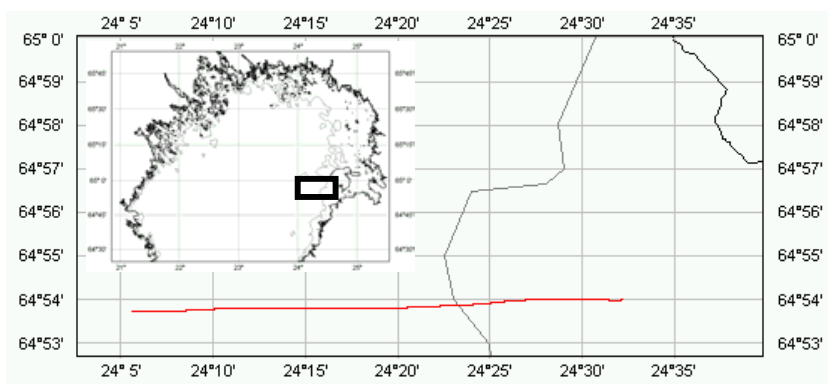

Figure 1: Map of the flight track in the Bay of Bothnia (red), with the $10 \mathrm{~m}$ isobath (grey) and the island of Hailuoto in the right top. 


\section{Helicopter EM thickness sounding}

An EM system consists of an assembly of coils for the transmission and reception of low-frequency EM fields, and a laser altimeter. The EM components are sensitive to the sensors height above the conductive sea water surface, while the sensors altitude above the ice or snow surface is determined with the laser altimeter. Over sea ice, the water surface coincides with the ice underside. Therefore, the difference of the height measurements of both components corresponds to the ice-plus-snow or total thickness (Figure 2; Haas, 1998).

We used a small, lightweight, helicopter-borne EM Bird, $3.5 \mathrm{~m}$ long and weighing $100 \mathrm{~kg}$. It was suspended $20 \mathrm{~m}$ below the helicopter and towed at heights of 10 to $20 \mathrm{~m}$ above the ice surface. The EM bird operates at frequencies of $\mathrm{f} 1=3.68$ and $\mathrm{f} 2=112 \mathrm{kHz}$, with a coil spacing of 2.7 and $2.1 \mathrm{~m}$, respectively. Signal generation, reception, and processing are fully digital, maximising signal-to-noise ratio. The EM system is calibrated by means of internal calibration coils with a known response. EM sampling frequency is $10 \mathrm{~Hz}$, corresponding to a measurement point spacing of approximately 3 to $4 \mathrm{~m}$. Measurements are interrupted every 15 to 20 minutes by ascents to high altitude, to monitor electrical system drift.

For the thickness computation shown in this paper we used the in-phase and quadrature components (real and imaginary parts) of $\mathrm{fl}$ and the inphase component of $\mathrm{f} 2$. Thickness was retrieved form each channel individually by means of a one-dimensional inversion of EM Bird height above the water surface (see below). Ice thickness is computed by subtracting the laser height measurement over sea ice from the inverted height above the water surface which coincides with the ice underside (Figure 2; Haas, 1998).

Comparison with drill-hole data shows that the EM derived ice thicknesses agree well within $\pm 0.1 \mathrm{~m}$ over level ice. However, the accuracy is worse over ridges. Because the low-frequency EM field is diffusive, its strength represents the average thickness of an area of 3.7 times the instruments altitude above the ice surface (Kovacs et al., 1995; Reid et al., 2005). Due to this "footprint", the maximum ridge thickness can be underestimated by as much as $50 \%$ in the worst cases, depending on the geometry and consolidation of the ridge keel (Haas and Jochmann, 2003).

\section{EM modelling}

The EM signal over any underground can be exactly calculated if the conductivity distribution is known (Kovacs et al., 1987; Ward and Hohmann, 1988). Here, we use a one-dimensional model with horizontal layers of air, ice, water, and seafloor. The EM response is given as relative secondary EM field strength, the quotient of secondary and primary magnetic field strength $\mathrm{H}_{\mathrm{s}} / \mathrm{H}_{\mathrm{p}}$. We have performed two different model runs, where the conductivities of the ice and water have been set to 0 and $340 \mathrm{mS} / \mathrm{m}$, respectively, representing typical conditions in the Bay of Bothnia and Caspian Sea: First, as the ice thickness measurement is essentially a measurement of bird height above the water surface (Figure 2), we calculate the EM signal just for a simple model of varying bird height above an infinitely thick layer of water. In this case, ice thickness is set to zero and due to the infinitely thick water layer, the seafloor is not sensed by the EM measurement.

Second, we investigate the effect of shallow water on the EM signal, with an ice thickness of $0 \mathrm{~m}$ and an infinitely thick layer of sediment or rock with a conductivity of 10 $\mathrm{mS} / \mathrm{m}$, representative of the sea floor. It should be noted that this is a worst case scenario, as seafloor conductivities can be much higher in most cases, and therefore the seafloor signal would be more similar to the seawater signal.

With the model computations, the full seafloor response can be computed individually for each channel. In the EM sounding community, it is also common to calculate an approximate penetration depth which is called the skin depth, dependent on signal frequency $f$ and the layers conductivity $\sigma$.

$$
\text { Skin depth } \approx 503 \sqrt{1 / \sigma f}
$$

Commonly it is assumed that layers below this depth generate no significant EM signal. In our case, with a water conductivity of $340 \mathrm{mS} / \mathrm{m}$ and frequencies of 3.68 and 112 $\mathrm{kHz}$, the skin depth amounts to 14.2 and $2.6 \mathrm{~m}$, respectively. This means than below this depth the seafloor would not affect the sea ice thickness retrieval.

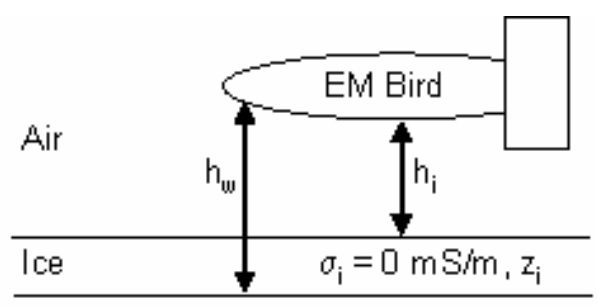

$$
\begin{array}{ll}
\text { Water } & \sigma_{w}=340 \mathrm{mS} / \mathrm{m}, \mathrm{z}_{\mathrm{w}} \\
\hline \begin{array}{l}
\text { Sediment } \\
\text { Rock }
\end{array} & \sigma_{\mathrm{s}}=0.1 \mathrm{mS} / \mathrm{m}, \mathrm{z}_{\mathrm{s}}=\infty
\end{array}
$$

Figure 2: Layering of air, ice, water, and seafloor used for the model computations. $\sigma_{j}$ are the respective conductivities, and $z_{j}$ the layer thicknesses. $h_{i}$ and $h_{w}$ are the bird height above the ice and water surface, respectively, and $z_{i}=h_{w}-h_{i}$ is total ice thickness.

\section{RESULTS}

\section{Model results}

Figure 3 shows the calculated EM response for all four channels of our EM Bird at varying bird altitude over a layer of seawater with a conductivity of $340 \mathrm{mS} / \mathrm{m}$, representative seawater with a salinity of $3.4 \mathrm{ppt}$. The main feature is the negative exponential decrease of the EM signal with increasing bird altitude. However, due to the low conductivity sea water, there are several differences to the usual case of high salinity Arctic sea water: For the low frequency of $3.68 \mathrm{kHz}$, the quadrature signal is larger than the inphase signal for bird heights less than $15 \mathrm{~m}$. Therefore, the quadrature channel is more suitable for ice thickness estimates than the inphase signal. However, the inphase signal of the high frequency channel of $112 \mathrm{kHz}$ is even higher than any signal of the low frequency for all heights 
under discussion here. The larger signal strength implies higher signal dynamics (gradients) and therefore a higher sensitivity to height changes or ice thickness changes (Figure 2). Therefore, the results shown in Figure 3 suggest to use the inphase component of the high frequency to derive ice thickness over brackish water.

The model curves provide the general means of computing the height of the bird above the water surface or ice underside from a measurement of each component of EM field strength at a certain height above the water (Haas, 1998).

The effect of varying water depth on the EM signal is shown in Figure 4, for bird altitudes of 10, 15, and $20 \mathrm{~m}$, respectively. The low frequency signal of $3.68 \mathrm{kHz}$ is strongly affected by induction in the sea floor (Figure 4a). For depths less than 15 to $20 \mathrm{~m}$, the inphase component is smaller than the signal for infinitely deep water. The quadrature signal increases slightly with decreasing water depth below 15 to $20 \mathrm{~m}$. For depths below 5 to $10 \mathrm{~m}$, the quadrature signal strongly decreases towards zero. The graph shows the same feature as Figure 3, i.e. decreasing responses with increasing altitude. The effect of the seafloor decreases slightly for higher flying altitudes. As the quadrature component approaches the response of infinitely deep water at shallower depths than the inphase, its use is more preferable for the ice thickness retrievals than the inphase component.

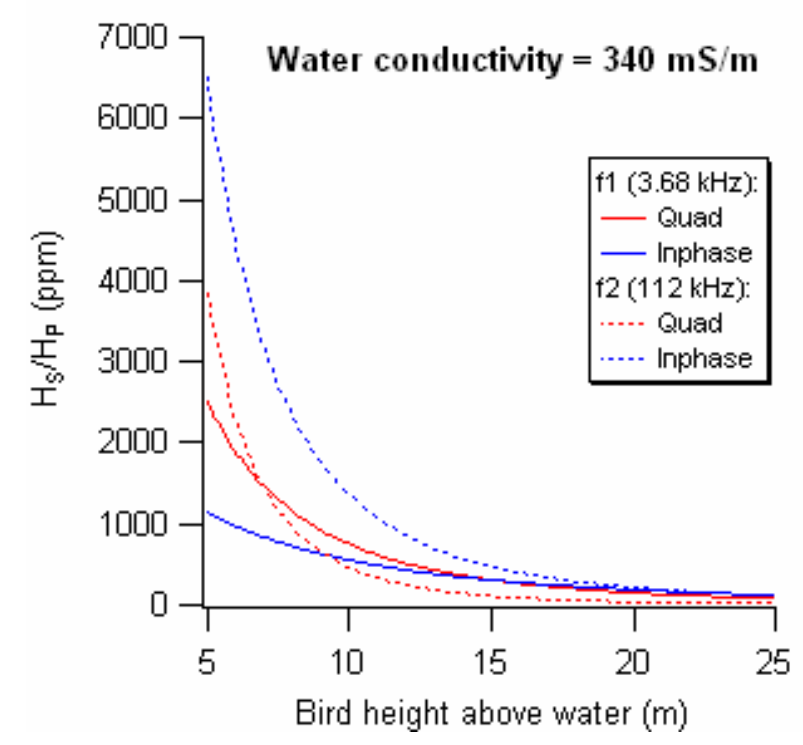

Figure 3: EM response (relative secondary EM field strength $\mathrm{H}_{\mathrm{s}} / \mathrm{H}_{\mathrm{p}}$ ) for varying bird heights over brackish sea water with a conductivity of $340 \mathrm{mS} / \mathrm{m}$, for the four channels of our EM Bird.
The high frequency signal in Figure $4 \mathrm{~b}$ is much less affected by the seafloor for water deeper than 4-6 m. Both inphase and quadrature signals slightly increase with decreasing water depth down to 1 to $2 \mathrm{~m}$, before they sharply decrease with shallower depths.

The model results demonstrate that the high frequency components are less influenced by the seafloor signal in shallow water. Results are in good agreement with the skin depth computed above for both channels. The high frequency inphase signal is superior to the lower frequency channels because over brackish water it yields the strongest signals, and it is not affected by the seafloor conductivity for water deeper than 4 to $6 \mathrm{~m}$.

a)

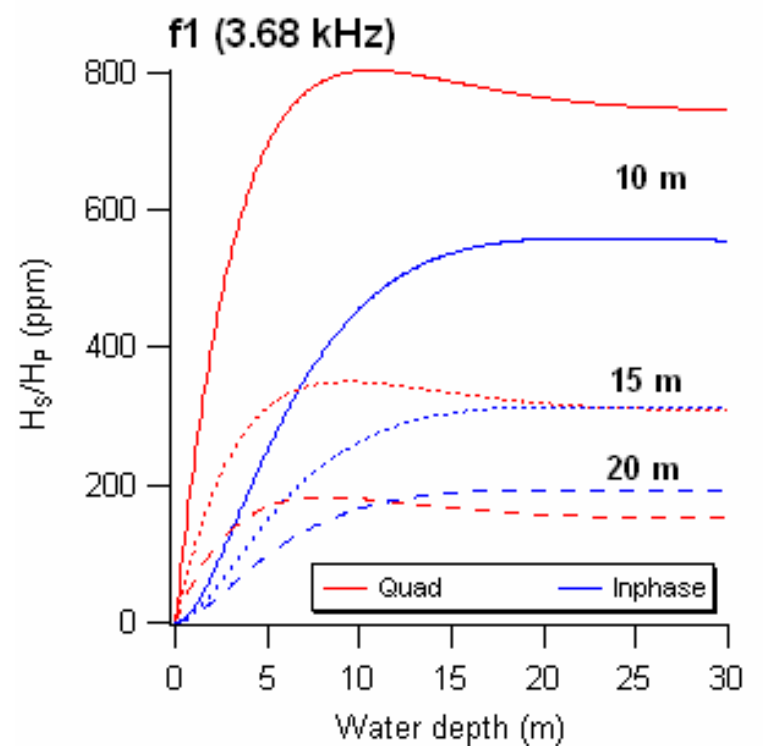

b)

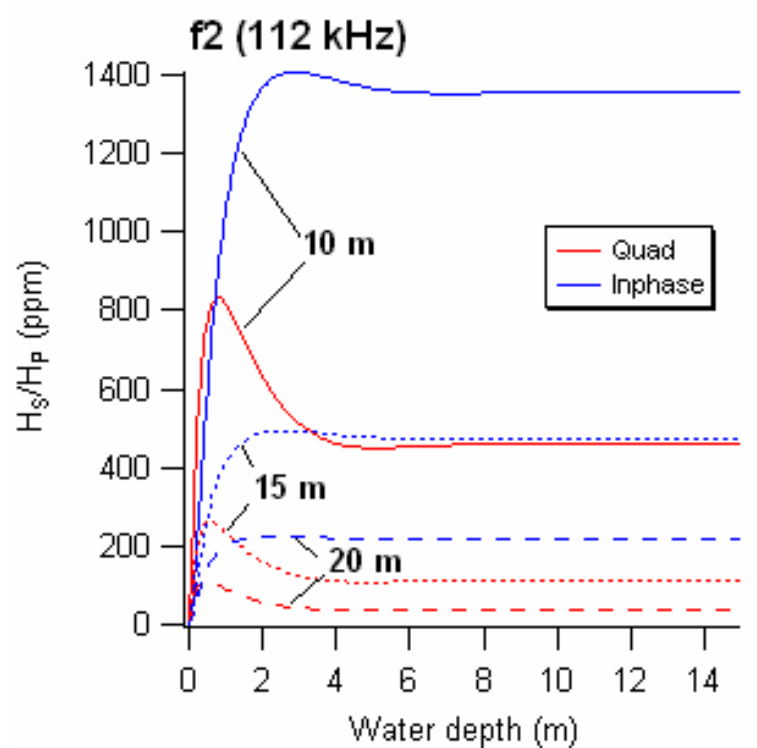

Figure 4: EM response (relative secondary EM field strength $\mathrm{H}_{\mathrm{s}} / \mathrm{H}_{\mathrm{p}}$ ) for varying depths of brackish sea water with a conductivity of $340 \mathrm{mS} / \mathrm{m}$, a seafloor conductivity of $10 \mathrm{mS} / \mathrm{m}$, and variable bird altitudes of 10,15 , and $20 \mathrm{~m}$. Ice thickness is set to zero. a) Low frequency inphase and quadrature; b) High frequency inphase and quadrature. Note different $x$-axis scales in $a$ ) and $b$ )! 


\section{Measured responses over brackish water}

Figure 5 compares the measured EM responses with the model curves from Figure 3. The quadrature component of the high frequency signal is not shown because it was too noisy and generally is technically not operational.

Measurements at different heights are obtained because the helicopter is unable to maintain a constant height, and therefore the bird altitude varies between 10 and $25 \mathrm{~m}$ during the flight (Figure 5). The data can be separated into two branches: While open water measurements at different bird heights agree well with the model curves, the presence of sea ice leads to a reduction of the measured EM signal at a given laser height. Therefore the scattered cloud of data points below the model curve represents measurements over ice. Ice thickness is computed by subtracting the laser height measurement over sea ice from the model curve (Figure 2; Haas, 1998). It can also be visually estimated from the horizontal distance between each EM measurement and the model curve. The thickness computation assumes a negligible sea ice conductivity, which is realistic for ice grown in the Baltic and Caspian Seas.

The data presented in Figure 5 agrees well with the results of the modelling in Figure 3: First, the open water measurements are well fit by the model curves, also demonstrating good calibration of the system. Second, the measured secondary field strength is largest for the inphase component of the $112 \mathrm{kHz}$ signal, and second highest for the quadrature component of the $3.68 \mathrm{kHz}$ signal.

\section{Thickness retrievals over shallow water}

Most of the discussed thickness profile has been obtained over water deeper than $15 \mathrm{~m}$. Therefore, the majority of the data shown in Figure 5 agrees well with the model curves for indefinitely deep water.

Figure 6 shows the computed ice thickness for the easternmost flight track in Figure 1, where the $10 \mathrm{~m}$ isobath was crossed at approximately $24.38^{\circ} \mathrm{E}$. Ice thickness has been calculated individually for each channel as described above (Figures $2 \& 5$ ). Ice thicknesses retrieved from the Quadrature(f1) and Inphase(f2) channels agree well, except between 24.45 and $24.50^{\circ} \mathrm{E}$. However, ice thicknesses retrieved from Inphase(f1) are much larger east of $24.30^{\circ} \mathrm{E}$. There, water depths actually are less than $15 \mathrm{~m}$, and therefore the EM signal is affected by induction in the seafloor. As can be seen from the model curves in Figure 4a, the inphase component of the low frequency signal becomes much smaller for shallow water. Smaller signals results in overestimates of ice thickness for a given bird height, as can be seen from the data in Figure 5.

Between 24.45 and $24.50^{\circ} \mathrm{E}$, the Finish Hydrographic Office sea chart shows water depths less than $5 \mathrm{~m}$. Therefore, even the quadrature component of the low frequency is affected by significant induction in the seafloor (Figure 4), and therefore the measured EM signal is lower than for indefinitely deep water, resulting in an overestimation of ice thickness from that component, too (Figure 5). Both Quadrature(f1) and Inphase(f2) show well a flaw lead with zero ice thickness at $24.41^{\circ} \mathrm{E}$ in front of the fast ice edge to the east. a)

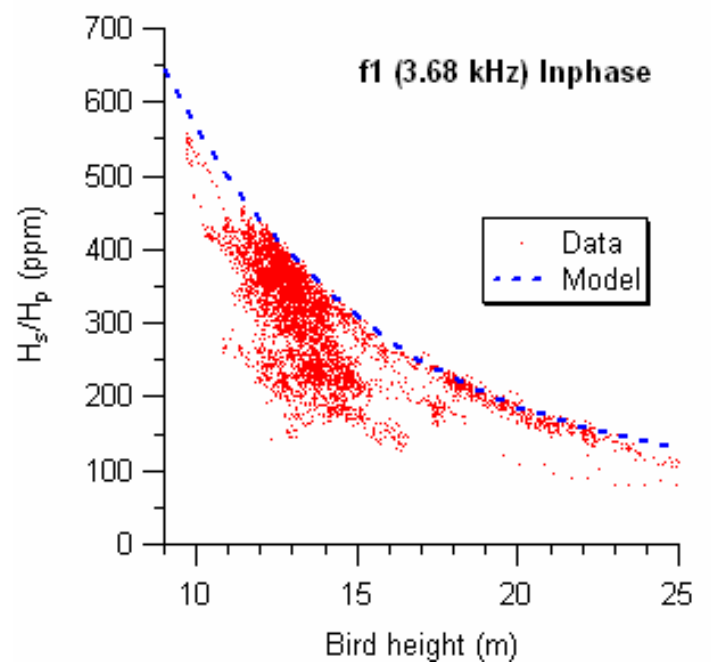

b)

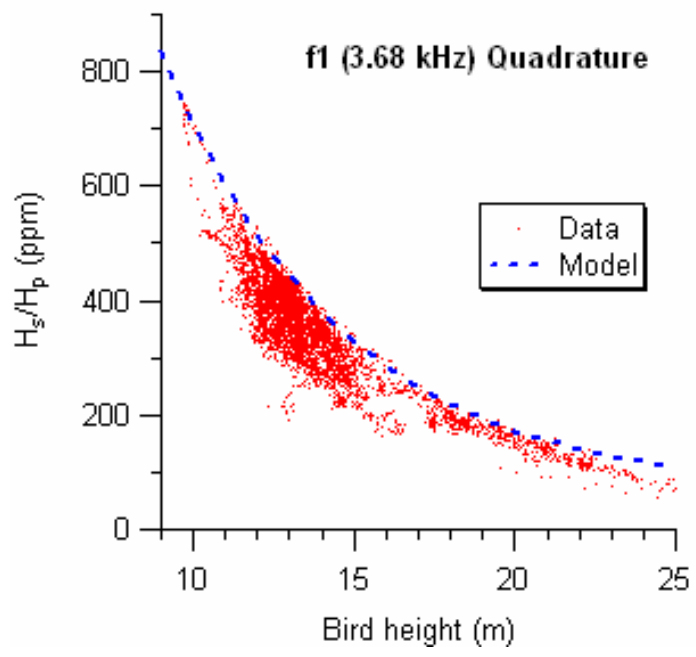

c)

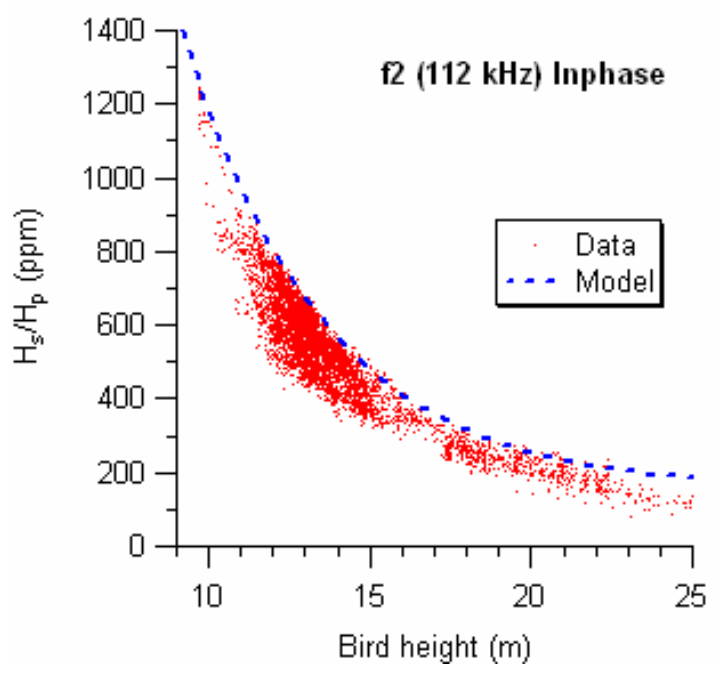

Figure 5: Measured calibrated EM signal $\mathrm{H}_{\mathrm{s}}$ as a function of bird height above the ice surface over the ice-covered Bay of Bothnia with a sea water conductivity of $340 \mathrm{mS} / \mathrm{m}$. a) Inphase, $3.6 \mathrm{kHz}$; b) Quadrature $3.68 \mathrm{kHz}$; c) Inphase $112 \mathrm{kHz}$. Model curves have been computed for a seawater conductivity of $340 \mathrm{mS} / \mathrm{m}$ (cf. Figure 3). 


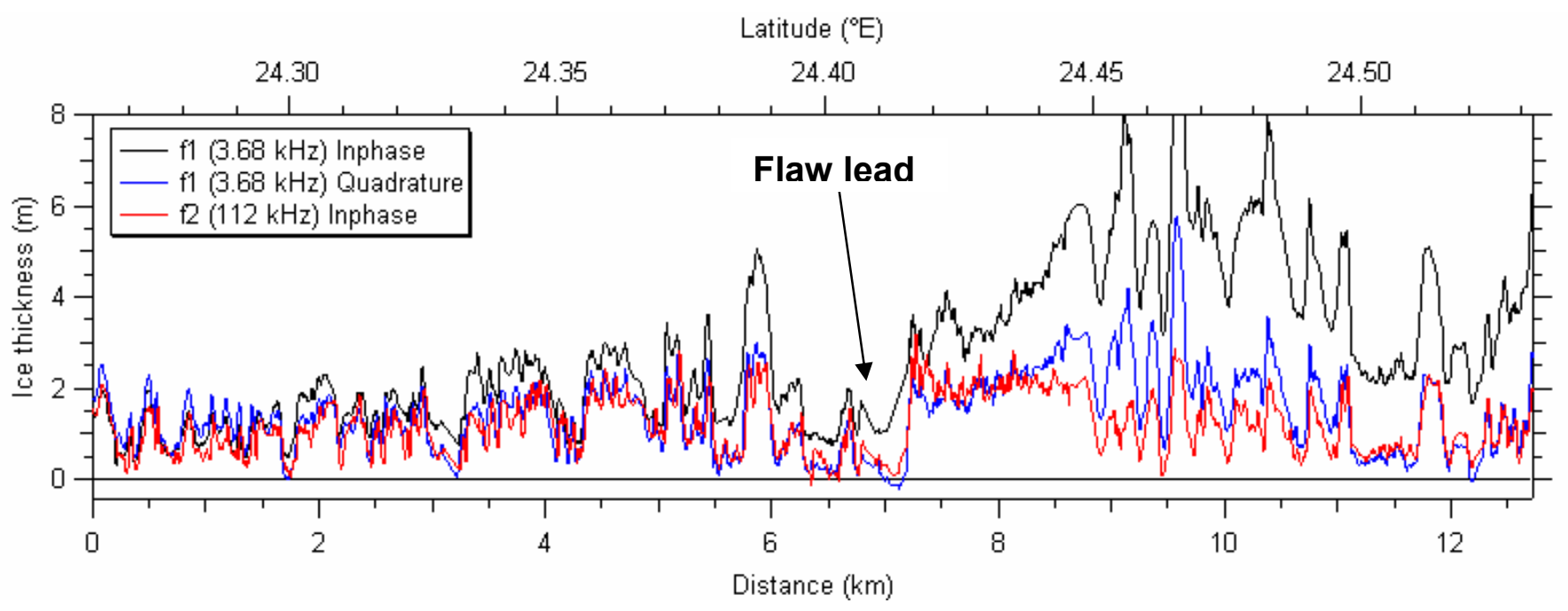

Figure 6: Ice thickness profiles (snow plus ice thickness) of the eastern flight track in Figure 1, obtained form individual inversion of the inphase and quadrature components of the low frequency signal, and inphase component of the high frequency signal. The $10 \mathrm{~m}$ isobath crosses the profile at approximately $24.38^{\circ} \mathrm{E}$.

\section{DISCUSSION}

By means of model computations and field data, we have shown the great value of a high frequency EM channel for the determination of sea ice thickness in shallow, brackish water. A comparison of model results and data shows good agreement and demonstrates the good calibration of our EM Bird. However, it should be noted that the $112 \mathrm{kHz}$ of our bird is a very high frequency compared with conventional geophysical EM systems. With lower frequencies, the minimum water depth below which reliable thickness measurements are still possible is deeper.

The reason for the common use of lower frequencies is that high frequency signals still present a technological challenge, as at such high frequencies it is difficult to generate a sufficiently strong primary field. As a consequence, the high frequency data are often very noisy, as is often the case with our bird, too. Therefore, the example in Figure 6 is an exceptionally good one. However, we are developing measures to improve the signal-to-noise ration of the high frequency channels, too.

The different sensitivities of the high and low frequency signals to shallow water depths call for using a full geophysical inversion procedure to compute ice thickness and water depth at once (Kovacs et al., 1987). This would also prevent from deriving too large thicknesses if the shallowness of the water was unknown. However, inversion procedures are complicated to implement, and are sensitive to noise and small calibration errors. Generally, with our one-dimensional inversion of just bird height the most accurate results can be obtained.

Instead, our data suggest a two-step procedure to derive ice thickness and water depth for water depths between 4 to $15 \mathrm{~m}$. First, ice thickness can be obtained from the inphase component of the high frequency signal. Then, ice thickness can be added to the measured bird height, to yield bird height above the water surface. Finally, by inversion of a large number of model curves for different bird heights like in Figure 4, water depth can be determined. For water depths below 15 to $20 \mathrm{~m}$, the sea floor does not induce a high enough signal, and therefore it cannot be determined any more. However, then, all ice thicknesses derived form the different channels will agree.

\section{CONCLUSIONS}

By means of model results and field data, we have shown that our EM bird using signal frequencies of 3.68 and $112 \mathrm{kHz}$ is capable to perform accurate sea ice thickness measurements in brackish water. The quadrature component of the low frequency signal and the inphase component of the high frequency are more capable than the inphase component of the low frequency signal with sea water salinities down to 3 ppt. However, the high frequency components of our bird are often very noisy. The low frequency components are affected by the seafloor signal when the water is less than 15 to $20 \mathrm{~m}$ deep. With the high frequency channels, ice thickness measurements are possible in water as shallow as 4 to $6 \mathrm{~m}$. For shallower water, the signal frequency had to be even higher. A combination of the low and high signal frequency allows the determination of both, ice thickness and water depth. To avoid thickness errors due to shallow water, it is also possible to perform thickness surveys in the ice free season, to obtain a kind of background signal. This can then be subtracted from the signals of measurements along the same flight tracks when the water is ice covered.

\section{ACKNOWLEDGEMENTS}

We are very grateful to Helitour Oy pilot Rene Koivisto. The campaign was carried out with support of Alfred Wegener Institutes airborne EM team Andi Pfaffling, Wolfgang Dierking, and Torge Martin. Data were processed 
by Volker Leinweber. IRIS is EU project No. EVK3-CT2002-00833.

\section{REFERENCES}

Haas, C., 1998, "Evaluation of ship-based electromagnetic-inductive thickness measurements of summer sea-ice in the Bellingshausen and Amundsen Seas, Antarctica", Cold Regions Science and Technology, 27, 116.

Haas, C., Rupp, K-H., Uuskallio, A., 1999, "Comparison of along track EM ice thickness profiles with ship performance data", Proc 15th Int Conf on Port and Ocean Engineering Under Arctic Conditions, Espoo, Finland, 1999, Helsinki Univ Techn, Ship Lab, 1, 343-353.

Haas, C., and Jochmann, P., 2003, "Continuous EM and ULS thickness profiling in support of ice force measurements". Proceedings of the 17th International Conference on Port and Ocean Engineering under Arctic Conditions, POAC '03, Trondheim, Norway, Department of Civil and Transport Engineering, Norwegian University of Science and Technology NTNU, Trondheim, Norway,2, 849-856.

Haas, C., 2004 "Airborne EM sea-ice thickness profiling over brackish Baltic sea water", Proceedings of the 17th international IAHR symposium on ice, June 21-25, 2004, St. Petersburg, Russia, All-Russian Research Institute of Hydraulic Engineering (VNIIG), Saint Petersburg, Russia, 2, 12-17.

Kovacs, A., Valleau, N.C, and Holladay, J.S., 1987, "Airborne electromagnetic sounding of sea ice thickness and sub-ice bathymetry". Cold Regions Science and Technology, 14, 289-311.

Kovacs, A., and Holladay, J. S., 1990, "Sea-ice thickness measurements using a small airborne electromagnetic sounding system", Geophysics, 55, 13271337.

Multala, J., Hautaniemi, H., Oksama, M., Leppäranta, M., Haapala, J., Herlevi, A., Riska, K., and Lensu, M., 1996, "An airborne electromagnetic system on a fixed wing aircraft for sea ice thickness mapping”, Cold Reg. Sci. Techn., 24, 355-373.

Prinsenberg, S.J., and Holladay, J.S., 1993, "Using airborne electromagnetic ice thickness sensor to validate remotely sensed marginal ice zone properties", Port and ocean engineering under arctic conditions (POAC 93), HSVA (Ed), Vol. 2, 936-948.

Ward, S. H., and Hohmann. G.W., 1988, "Electromagnetic theory for geophysical applications", Electromagnetic methods in applied geophysics-theory, volume 1, SEG Monograph, (M.N. Nabighian, Ed.), Vol. 3, 131-313. 